\title{
BI-DIRECTIONAL PSEUDODYNAMIC TESTS OF BRIDGE PIERS DESIGNED TO DIFFERENT STANDARDS
}

\author{
R. P. Dhakal ${ }^{1}$, J. B. Mander ${ }^{2}$ and N. Mashiko ${ }^{3}$
}

\begin{abstract}
Circular reinforced concrete highway bridge piers, designed in accordance with the requirements of Caltrans, New Zealand and Japanese specifications, are experimentally investigated to assess their seismic performance. Pseudodynamic test procedures are developed to perform experiments on $30 \%$ scaled models of the three prototype bridge piers. Each specimen is subjected to a sequence of three different earthquake ground motions scaled appropriately to represent: (i) the Design Basis Earthquake (DBE) with a 90 percent non-exceedance probability; (ii) the Maximum Considered Earthquake (MCE) with a 50 percent non-exceedance probability; and (iii) the MCE with a 90 percent non-exceedance probability. Damage states after the earthquakes are assessed and mapped for seismic risk assessment. The damage outcomes and the corresponding seismic risks validate the objectives of the performance based design codes of the three countries. The results show that when bridge piers are designed to the specifications of each of the three countries, satisfactory performance with only slight to moderate damage can be expected for DBE. For the MCE, severe damage without collapse is likely for the Caltrans and Japanese piers. However, the NZ pier may not be able to survive MCE motions with sufficient reliability to ensure the preservation of life-safety.
\end{abstract}

\section{Introduction}

Recent major earthquakes such as the 1994 Northridge and the 1995 Hyogoken-Nanbu (Kobe) events had a severe impact on the serviceability of bridges. Consequently, there has been a growing interest in comparing the seismic performance of bridges designed according to the codes and standards of different countries. This is because both the loading requirements and structural detailing procedures vary considerably, even though the magnitude of hazard exposure may be similar. As part of a cooperative four-country international project, Tanabe [1999] designed four bridge piers, in accordance with Caltrans, New Zealand, Japanese and European design standards. The main purpose of this international project was to identify differences in the cross-section dimensions and reinforcing details, to clarify the reasons for these differences, and to assess the likely seismic performance by computational means. This previous comparative research was restricted to uni-directional earthquake motions. Given that simultaneous bidirectional earthquake motions occur in reality, and computational predictions may differ from real response due to modelling simplifications, it is considered desirable to conduct an experimental investigation of the seismic response of bridge piers including bi-directional effects.

Although simplified test procedures such as quasi-static and high-speed cyclic tests [Dhakal and Pan 2003] exist for general experimental studies of structural behaviour, more advanced test procedures such as pseudo-dynamic tests (referred to as PD tests hereafter) or shaking table tests are needed to experimentally assess the expected seismic performance of structures. PD tests offer an experimental technique to measure response of structures to previously observed earthquake motions without the need for small scale shaking table tests that

\footnotetext{
${ }^{1}$ Senior Lecturer, Dept. of Civil Engineering, University of Canterbury, Private Bag 4800, Christchurch, NZ

${ }^{2}$ Professor, Dept. of Civil Engineering, University of Canterbury, Private Bag 4800, Christchurch, NZ

${ }^{3}$ Graduate Student, Dept. of Civil Engineering, University of Canterbury, Private Bag 4800, Christchurch, NZ
} 
are and more demanding in terms of resources. Although quasi-static cyclic loading tests are simple to conduct, they suffer from the difficulty of interpreting the results with respect to the structure they represent. PD tests avoid this by giving a more balanced view of seismic capacity versus demand [Dhakal et al 2006].

The PD test method was first developed by Takanashi et al [1975] for experimentally assessing the seismic performance of critical elements using real earthquake ground motion as input. Since then, enhanced versions of PD test procedures have been suggested by many researchers to improve the efficiency and to widen the scope of the PD test method [Horiuchi et al 1999; Nakashima and Masaoka 1999; Darby et al 2001; Bonelli and Bursi 2004; Pan et al 2005; Zhang et al 2005]. In the last decade, researchers have successfully conducted PD tests on bridge piers [Mutsuyoshi et al 1994; Zatar and Mutsuyoshi 2002; Hayakawa et al 2003], bridges [Pinto et al 2004], reinforced concrete buildings [Molina et al 1999; Paultre et al 2003], steel frames [Molina et al 2004] and masonry-infilled RC frames [Negro and Verzeletti 1996; Mosalam et al 1998; Colangelo 2005] to investigate their performance under real earthquakes.

There have also been a few attempts to conduct bi-directional PD tests [Mutsuyoshi et al 1994; Molina et al 1999]. Bi-directional PD tests on bridge piers [Hayakawa et al 2003] have shown that both strength and deformability in a given direction deteriorates as a result of displacements induced by orthogonal motion; this is often referred to as the "simultaneous bidirectional interaction effect". Because this effect is not well understood, there is no consensus amongst design codes as to how orthogonal seismic loading effects should be handled.

In this study, the seismic performance of three highway bridge piers designed and detailed according to the prevailing seismic design standards of California [Caltrans 1994], New Zealand [NZS3101 1995] and Japan [JSCE 1994] are compared. For the experimental investigation, specimens representing 30\% scaled models of these three bridge piers were constructed and tested using the PD test method. Bi-directional PD tests were carried out on these specimens using three earthquakes chosen based on the results of a rigorous Incremental Dynamic Analysis (IDA) [Vamvatsikos and Cornell 2004]. Observed damage to the piers is assessed in terms of post-earthquake serviceability following the damage classification of HAZUS [Mander and Basoz 1999]. The observed seismic performance of each pier is then compared against each other.

\section{Experimental Details}

\section{Properties of the Prototype Piers}

Square reinforced concrete bridge piers designed previously [Tanabe 1999] for the same level of seismic hazard using the Caltrans [1994], NZS3101 [1995] and JSCE [1994] standards were adopted as the initial basis of this study. As shown in Fig. 1, the prototype bridge design consists of a common $10 \mathrm{~m}$ wide superstructure (deck) supported on a $7 \mathrm{~m}$ high pier. Although the design basis earthquake (DBE) with $10 \%$ probability of occurrence in 50 years (i.e. return period of 475 years) may correspond to different intensities in different countries, a common DBE having peak ground acceleration (PGA) of $0.4 \mathrm{~g}$ was adopted for designing these three piers irrespective of the location so that the difference in response could be attributed to the difference in design provisions only.

In this study, the cross-section of the three square piers was changed to circular, without violating the design recommendations of the corresponding standards. The properties of the three prototype circular bridge piers designed and detailed using these three different design standards are tabulated in Table 1. Elasto-plastic push-over curves of the three prototypes are shown in Fig. 
1, which also shows push-over curves obtained by moment-curvature based section analyses performed using the design strengths and the measured strengths of the materials.

\section{Design and Fabrication of Test Specimens}

In order to conduct PD tests, reduced scale models detailed at 30 percent of full scale were prepared for all three prototype piers. The geometrical dimensions, reinforcement details and design parameters of the three specimens are listed in Table 1. The longitudinal and transverse reinforcement ratios provided in the scaled specimens were aimed at keeping the same proportional force capacities as in the prototypes. Each specimen was constructed in three phases:

(i) the rectangular base block; (ii) the circular column; and (iii) the rectangular head block. The concrete was poured separately for each part. Between the pourings of the base block and the pier, strain gauges were attached to the spirals over a range of $0.2 \mathrm{D}$ (where $\mathrm{D}$ is the diameter of the pier) starting from $0.1 \mathrm{D}$ above the base. To facilitate the measurement of curvature, threaded rods (6 $\mathrm{mm}$ diameter) were welded to the longitudinal bars over the lower portion of the pier. Cardboard tube formwork was placed and held securely over the tied reinforcing cages, then the concrete was cast. The specimens were tested well after 28 days of curing. The measured values of compressive strength of concrete and yield strength of the longitudinal bars and spirals are shown in Table 1.

\section{Test Setup and Instrumentation}

Fig. 2(a) presents an East-West (EW) elevation view from the north direction of a specimen set up in the test rig. As the loading applied to the specimen in the PD test was bidirectional, a similar view existed in the North-South (NS) direction as well. For further clarification, a plan view of the test setup is shown in Fig. 2(b). The specimens were set in the DARTEC universal testing machine. A constant axial force of $630 \mathrm{kN}$ was applied via ball joints attached to the top and bottom plattens and the specimens. L-shaped loading frames and counterweight baskets were attached to the base block of the specimen in each direction. These were connected by $30 \mathrm{~mm}$ diameter high-strength threaded bars. Lateral loads were applied in both EW and NS directions via $800 \mathrm{kN}$ hydraulic actuators that were connected to the specimen head block and L-shaped load frames via universal joints.

Fig. 3 shows the instrumentation and data acquisition system used in the test. A $1000 \mathrm{kN}$ capacity load cell was installed in-series with the actuator to measure the load applied in each lateral loading direction. Two rotary potentiometers were attached to the two adjacent sides of the pier at $2.1 \mathrm{~m}$ from the bottom to measure the total lateral displacements in the two directions. As shown in the Fig. 3, the lateral displacement profiles of each specimen was measured using three pairs of rotary potentiometers at different locations along the height of the specimen. Curvature, rotation and longitudinal strains in the plastic hinge region were also measured with the help of five layers of EW and NS pairs of spring loaded potentiometers attached to the four sides of the specimens at several locations near the base of the piers. Strain gauges were also fixed to the spirals to enable the estimation of confining stress.

\section{Pseudo-dynamic (PD) Test Procedure}

The PD test method consists of two parts. First, the structure is represented "virtually" as a computational model, for which the equations of motion are formulated and analysed in a normal fashion. Next, the tangential stiffness of the structure is measured physically at each timestep increment and an updated value is used in subsequent computational modelling. As the PD 
test is conducted at a much slower rate than in real time, the inertial effect on the physical test specimen does not exist, but needs to be accounted for computationally.

Fig. 4 presents the concept of the PD test at the $(n+1)^{\text {th }}$ time step. To conduct the PD test, the overall setup needs to be divided into two main physical systems which are linked together. The first is an "analysis and control system", where the displacement response of the prototype pier is computed based on the nonlinear equation of motion in incremental form, which can be written for the $\mathrm{n}^{\text {th }}$ time step as $m \ddot{x}_{n}+c \dot{x}_{n}+F_{n-1}+k_{n-1}\left(x_{n}-x_{n-1}\right)=-m a_{g(n)}$. The result feeds forward the position for the next step $\left(x_{n}\right)$ to the second system known as the "experimental system", which moves the specimen to the desired position. In return, the "experimental system" feeds back the measured restoring force $\left(F_{n}\right)$ and the tangential stiffness $\left(k_{n}\right)$ to the "analysis and control system" to be used in the equation of motion. At the next time step, the ground acceleration $a_{g(n+1)}$ is extracted from the stored acceleration time history of the earthquake and the analysis is repeated. This cyclic procedure is repeated until the input earthquake data set is terminated.

The values in the "analysis and control system" always correspond to the full-scale prototype dimensions, whereas the displacements are scaled $30 \%$ only when sent to the "experimental system". On the other hand, the lateral loads measured during the course of the experiment are scaled up by a factor of 11.11 (i.e. $1 / 0.3^{2}$ ) before being sent back to the "analysis and control system". Consequently, there are several matters requiring attention in planning PD tests which arise from reduced scale physical modelling. These include: (1) the time step increment, (2) the amplitude of input earthquake, (3) the mass of the superstructure, and (4) the damping factor. The scale factors for each of these parameters are decided in accordance with constant acceleration, constant stress and constant strain similitude.

Input values for the PD tests are the mass, the damping factor and the input earthquakes in time series format. The mass corresponds to the superstructure weight $(7000 \mathrm{kN})$, and the scale factor (0.3) need not be considered for the mass because the analysis in the PD test is conducted using the prototype properties. Damping equal to $5 \%$ of the critical was assumed. The incremental time step used in the input ground motion records and also used for the numerical integration in the PD algorithm was chosen as $0.03 \mathrm{sec}$.

\section{Loading Protocol}

Single level of assessment with one earthquake record of $\mathrm{PGA}=0.4 \mathrm{~g}$ representing DBE has been carried out analytically for all three prototype piers [Tanabe 1999]. As observed in Northridge (1994) and Kobe (1995) earthquakes, when earthquakes stronger than the one used in the design occur, structures are severely damaged. Therefore, the development of a seismic performance assessment method with two or three intensity levels of earthquakes is becoming the current trend. Here, following the multi-level seismic performance assessment methodology, seismic performance of the piers is experimentally investigated for three different levels of seismic hazard; the highest of which is an upper-bound Maximum Considered Earthquake (MCE) that has a $2 \%$ probability of occurrence in 50 years (i.e. return period of 2475 years).

The PD tests conducted in this study are bi-directional; i.e. seismic ground motions are applied in both EW and NS directions. The acceleration time-histories applied to the specimens are real ground motions in two mutually perpendicular directions recorded during recent earthquakes. Among a suite of 20 earthquake records, based on the results of a robust and comprehensive analytical process called the Incremental Dynamic Analysis (IDA) three records were identified to represent the DBE with $90 \%$ confidence (i.e. $10 \%$ exceedance probability), and 
the MCE with 50\% and 90\% confidences, respectively [Vamvatsikos and Cornell 2004; Dhakal et al 2006]. These records were chosen because they yielded a response from the piers which was close to the prescribed percentile $(50 \%$ or $90 \%)$ of the piers' responses to the 20 earthquakes scaled to the intensity of the corresponding hazard (DBE or MCE). Detail information on these three earthquake records, respectively designated as EQ1, EQ2 and EQ3, are given in Fig. 5. Note that the original ground acceleration history of these earthquake records have been scaled to obtain the PGA values corresponding to the seismic hazards represented; i.e. PGA $=0.4 \mathrm{~g}$ for $\mathrm{DBE}$ and $\mathrm{PGA}=0.8 \mathrm{~g}$ for $\mathrm{MCE}$ in this study.

These three scaled ground motion records were applied in sequence in an increasing order of severity. This enabled a one-off PD test to be conducted on a single scaled model to perform a comprehensive (multi-level) seismic performance assessment of the prototype pier. As shown in Fig. 5, the first $20 \mathrm{sec}$ of the first two earthquake records was used for the input ground motion, since the main shock occurs in this range. The three records were connected together with $5 \mathrm{sec}$ zero-acceleration period between them to measure residual drift.

\section{Experimental Results}

The performance of the piers to each of the three earthquake records is discussed in terms of the induced damage. The five damage states defined based on HAZUS damage classification [Mander and Basoz 1999] are used in this study to prescribe the damage of the bridge piers during and after each earthquake. These damage states are DS1 (no damage), DS2 (slight/minor damage), DS3 (moderate damage), DS4 (extensive damage) and DS5 (complete damage/collapse). The damage state descriptions are based on strain measurements and visual observations. Throughout this section, only the EW response of the bridge piers is discussed in detail since the critical earthquake component was aligned to the EW direction. The damage states inspected were yielding of bars, cracking, spalling of cover concrete, buckling of bars, and fracturing of bars. Yielding was judged after the tests from the data measured by the vertical potentiometers. In addition, the maximum lateral load, maximum drift and the residual drift measured during each earthquake are used in combination with the visually observed physical condition of the specimens to decide the damage states after each earthquake.

\section{Caltrans Pier}

Fig. 6 shows the PD test results of the Caltrans pier, showing (a) a plan view of the bidirectional orbit of the response drift; (b) load-displacement curves for the two directions; (c) the complete time-history of the response drift in the two directions; (d) photograph showing cover spalling at a drift of 3.7\%; and (e) photograph at the end of the PD test showing bar buckling along with crushing of core concrete. The seismic performance of the Caltrans pier is described below in detail based on the damage events observed during each record and damage states assigned to the specimen after each record.

\section{EQ1 with $P G A=0.4 g(0-20 \mathrm{sec})$}

During the first record $(\mathrm{EQ} 1$ with PGA $=0.4 \mathrm{~g})$, flexural cracks appeared near the base of the pier with a spacing of approximately $200 \mathrm{~mm}$. These cracks opened and closed alternately during the excitation, but finally closed at the end of the record. Calculating the strain profile from the externally measured curvatures, yielding of the first bar occurred at $5.6 \mathrm{sec}$ when the drift was $0.24 \%$ and the lateral load was $94 \mathrm{kN}$. As commonly expected in circular piers with reinforcing bars distributed in the perimeter, the lateral load kept increasing steadily after first 
yielding. At the maximum response at $13.1 \mathrm{sec}$, the lateral load was $232 \mathrm{kN}$ and the drift was $1.53 \%$. At the end of the record EQ1 (i.e. $20 \mathrm{sec}$ ), the residual drift was $0.12 \%$ in the EW direction and close to zero in the NS direction. At this stage, the specimen had crossed the elastic response limit but did not have residual damage despite yielding of the longitudinal bars. The damage state of the specimen after record EQ1 could be classified as DS2 (slight damage).

EQ2 with $P G A=0.8 g(25-45 \mathrm{sec})$

During the second record (EQ2 with PGA $=0.8 \mathrm{~g}$ ), more cracks emerged at the bottom of the specimen, especially in the lowermost one-diameter range (i.e. $600 \mathrm{~mm}$ ). These cracks, which were spaced approximately $50 \mathrm{~mm}$ apart, closed and opened alternately during the excitation. Despite the two-fold increase in PGA, the maximum response during the record EQ2 was only slightly larger than that in the previous record EQ1. The maximum drift during EQ2 record was $1.95 \%$ at $36 \mathrm{sec}$ when the lateral load reached $259 \mathrm{kN}$. At the end of the record (i.e. $45 \mathrm{sec}$ ), the residual drift was $0.13 \%$ in the EW direction. Concrete in the cross-section neither spalled nor crushed in this phase. Nevertheless, the flexural cracks did not close completely and a few closely spaced cracks were visible at the end of the record EQ2. The physical condition of the specimen suggested that the damage state was still in the "slight damage" category (i.e. DS2).

EQ3 with $P G A=0.8 g(50-95 \mathrm{sec})$

The third and the final record $(\mathrm{EQ} 3$ with $\mathrm{PGA}=0.8 \mathrm{~g}$ ) caused visibly severe damage to the specimen and the response was much larger than that due to the previous record (EQ2) despite having the same PGA. The record EQ3 induced a maximum drift of approximately $6 \%$ at about $71 \mathrm{sec}$, when the lateral load reached nearly $300 \mathrm{kN}$. During this phase, the cracks opened wider, and the cross-section deteriorated noticeably around the base of the specimen. As shown in Fig. 6(d), the cover concrete spalled off at $65 \mathrm{sec}$ when the drift was about $3.7 \%$ and the longitudinal bars buckled at $70 \mathrm{sec}$ when the specimen drifted 5.3\% laterally. At the end of record EQ3, the residual drift was $0.2 \%$ in the $\mathrm{EW}$ direction. As the buckling of several longitudinal bars led to an irreparable condition, the damage state at the end of the test was identified as DS4 (severe damage).

\section{Test Results of New Zealand Pier}

Fig. 7 shows the PD test results of the New Zealand pier, showing (a) a plan view of the bi-directional orbit of the response drift; (b) load-displacement curves for the two directions; (c) the complete time-history of the response drift in the two directions; (d) photograph showing bar buckling at a drift of $3.6 \%$; and (e) photograph at the end of the PD test showing low cycle fatigue fracture of longitudinal bars.

When judged from the longitudinal bar strain inferred by external instrumentation, yield occurred at $5.6 \mathrm{sec}$ when the drift exceeded $0.3 \%$ eastwards. The lateral load when the pier yielded was $63.3 \mathrm{kN}$. During the first earthquake record $(\mathrm{EQ} 1$ with $\mathrm{PGA}=0.4 \mathrm{~g}$ ) several horizontal cracks were observed approximately $150 \mathrm{~mm}$ apart, but these cracks closed after the record EQ1 finished. The maximum drift and lateral load measured were $1.65 \%$ at $13.83 \mathrm{sec}$ and $159 \mathrm{kN}$ at $6.24 \mathrm{sec}$, respectively. The residual drift was $0.17 \%$. The damage state after the $20 \mathrm{sec}$ EQ1 record was assessed as DS2 (slight damage), since the pier exceeded the yield limit but no spalling was apparent.

During the second earthquake record $(\mathrm{EQ} 2$ with $\mathrm{PGA}=0.8 \mathrm{~g})$ new horizontal cracks emerged at about $50 \mathrm{~mm}$ spacing over the two-diameter range (approximately $1 \mathrm{~m}$ ) from the 
bottom of the pier. The cracks were found to be more intensive than those formed during the record EQ1, but the residual crack width was still relatively small (not more than $0.2 \mathrm{~mm}$ ). The cover concrete remained in the same condition and no spalling was confirmed. The maximum drift of about $2.5 \%$ occurred at $36.9 \mathrm{sec}$, and the residual drift at the end of the record EQ2 (after $45 \mathrm{sec}$ ) was $0.25 \%$. The damage state after the record EQ2 was still assessed as DS2 (slight damage), the same as before the start of this record.

The important damage events observed during the final record (EQ3 with $\mathrm{PGA}=0.8 \mathrm{~g}$ ) were cover spalling, longitudinal bar buckling, and several spiral bar fractures occurred; this resulted in a rapid strength degradation forcing the termination of the test. Cover concrete spalling and longitudinal bar buckling were observed for the first time at $63.7 \mathrm{sec}$ with $2.5 \%$ drift and at $68.4 \mathrm{sec}$ with $3.6 \% \mathrm{drift}$, respectively. Subsequently, the first bar fracture occurred at 71.7 sec with $6.0 \%$ drift. The major degradation of strength started at $74.5 \mathrm{sec}$ when the top of the pier was at $6.5 \%$ drift. Thereafter, the lateral load showed $20 \%$ reduction (from $78.7 \mathrm{kN}$ to $62.6 \mathrm{kN}$ ), while the drift of the pier increased $1.75 \%$ (from $6.53 \%$ to $8.27 \%$ ). The strength degradation signalled a potential collapse of the pier and the test was terminated. It was clearly evident from the physical condition of the specimen after the test that the damage state was DS5 (complete damage).

\section{Test Results of Japanese Pier}

Fig. 8 shows the PD test results of the Japanese pier, showing (a) a plan view of the bidirectional orbit of the response drift; (b) load-displacement curves for the two directions; (c) the complete time-history of the response drift in the two directions; (d) photograph showing the beginning of cover spalling at a drift of 2.7\%; and (e) photograph at the end of the PD test showing the relatively intact pier.

The Japanese pier yielded when the drift reached $0.2 \%$ at $5.6 \mathrm{sec}$. During the first record (EQ1 with PGA $=0.4 \mathrm{~g}$ ), two principal horizontal cracks formed, one at the bottom of the pier and the other $300 \mathrm{~mm}$ from the bottom; however these cracks closed after $20 \mathrm{sec}$ when the record EQ1 finished. The maximum drift and the corresponding lateral load measured were $1.48 \%$ and $327 \mathrm{kN}$, respectively, at $13 \mathrm{sec}$. The residual drift after the record EQ1 was negligible (measured to be $0.05 \%$ ). Yielding of longitudinal bars suggested that the pier was in "slight damage" category (i.e. DS2) after the record EQ1.

During the second record (EQ2 with PGA $=0.8 \mathrm{~g}$ ), maximum drift of $1.76 \%$ was measured when the lateral load was $355 \mathrm{kN}$ at $30.2 \mathrm{sec}$. In this phase, more horizontal cracks appeared throughout the lower one-diameter region (i.e. $600 \mathrm{~mm}$ ) of the column; these cracks were spaced some $100 \mathrm{~mm}$ apart. Although these cracks were more intensive than those during the record EQ1, no residual cracks were visible after EQ2 terminated. The residual drift was measured to be $0.11 \%$ at the end of this phase. The cover concrete remained intact and no spalling was observed. Correspondingly, the damage state inspected after the record EQ2 was assessed to be DS2 (slight damage).

The extent of damage resulting from the final record (EQ3 with PGA $=0.8 \mathrm{~g}$ ) was restricted to cover concrete spalling, which occurred at $66 \mathrm{sec}$ at a drift of $2.7 \%$. The maximum response occurred at about $72 \mathrm{sec}$ when the drift exceeded $4.2 \%$ and the lateral load at this stage was about $390 \mathrm{kN}$. At the end of the test, the residual drift was still $0.11 \%$, same as that after the previous record EQ2. During this phase, neither buckling nor fracturing of the bars was noticed and the longitudinal bars remained intact. Even after the whole record finished, the core concrete was not damaged at all, and no cracks and gaps appeared around the longitudinal bars. Therefore, 
this bridge pier was apparently repairable simply by replacing the concrete at the area where the cover concrete peeled off. Accordingly, the damage state was assessed as DS3 (moderate damage).

\section{Comparison of the Three Piers' Performances}

Responses of each of the three piers in the EW direction under each of the three successive records are arranged separately in Fig. 9 to give nine force-displacement hysteresis curves along with three response drift time-histories. The load-displacement relationships in the first column of Fig. 9 show that all the bridge piers exhibited limited hysteresis response under the first record EQ1 with $\mathrm{PGA}=0.4 \mathrm{~g}$ (representing $\mathrm{DBE}$ ), and only a minimal residual drift remained at the end of EQ1. The stiffness of the New Zealand pier was less than that of the other two due to its smaller diameter and lower lateral strength, and the maximum displacement response of the Caltrans pier was slightly smaller than that of the other two piers.

As shown in Fig. 9(d)-1, the drift time-histories of the three piers are similar before the first positive peak at approximately $6.3 \mathrm{sec}$, but the responses of the three piers differed afterwards. The Caltrans and Japanese piers moved almost together throughout the duration of the record EQ1, but the NZ pier showed a consistently larger response than the other two. The second record $\mathrm{EQ} 2$ with $\mathrm{PGA}=0.8 \mathrm{~g}$ also attracted a significantly larger response from the NZ pier compared to the other two. As suggested by the hysteresis loops in the second column of Fig. 9, Caltrans and Japanese piers dissipated less energy than the NZ pier did. Furthermore, the NZ pier had a 2.5\% maximum drift, whereas the Japanese and Caltrans bridge piers responded within a $2 \%$ drift. As shown in Fig. 9(d)-2, the NZ pier swayed consistently more than the other two throughout the record EQ2, resulting in the largest residual drift among the three piers by the end of the record.

When subjected to the final and most severe earthquake record EQ3 with PGA $=0.8 \mathrm{~g}, \mathrm{NZ}$ pier failed completely before the completion of the earthquake. The Caltrans pier was severely and irreparably damaged but could sustain the whole record without collapse. The Japanese pier suffered only moderate damage and was in a repairable condition after the record. The first 14 sec of the record EQ3 showed similar response for all three piers. Then, the devastating part of the record hit the piers (see Fig. 9(d)-3). The NZ pier experienced 8\% drift, which was the maximum drift observed in the whole test series. Soon, the longitudinal bars started to fracture and the lateral load started to reduce sharply (see Fig. 9(b)-3) forcing the termination of the test. As can be seen in the third column of Fig. 9, the other two piers did not show any significant loss of lateral-load nor did they experience bar fracture. Hence, the tests with these two piers were continued for the whole duration of the record EQ3, which attracted $4.4 \%$ maximum drift from the Japanese pier and 6\% maximum drift from the Caltrans pier. Note that the damage due to the final record might have been exaggerated to some extent because of the residual damage from the previous records. Nevertheless, this carry over effect is overlooked in this test protocol because the amount of resources it saves compared to those required if three different specimens had to be tested against the three earthquake records easily outweighs the small discrepancy in the result interpretation.

\section{Application of the Test Results to Seismic Risk Assessment}

Figure 10 describes the seismic risk of the three bridge piers based on the PD test results (shown by the dark circles). In the plots, the vertical axis is the annual probability of earthquakes, and the horizontal axis is the maximum drift of the pier. The threshold of the first damage state 
DS1 (i.e., no damage) is assigned to the yielding drift obtained from section analysis using the measured material properties, whereas drifts larger than that will correspond to the higher damage states. The plots indicate that all three piers incur slight damage when subjected to the first two records. Two horizontal dashed lines at $P_{a} \sim 0.002$ and $P_{a} \sim 0.0004$ represent the two seismic hazard levels; i.e. DBE (475 years return period) and MCE (2475 years return period), respectively. Note that the three earthquakes used in the tests and analyses respectively represent the $90^{\text {th }}$ percentile DBE, median (i.e. $50^{\text {th }}$ percentile) MCE and $90^{\text {th }}$ percentile MCE. Hence, the maximum drift of the piers during the first record (EQ1) is plotted on the DBE line $\left(P_{a} \sim 0.002\right)$ and that during the next two records (EQ2 and EQ3) are plotted on the MCE line $\left(P_{a} \sim 0.0004\right)$.

Next, probabilistic curves representing the typical median and $90^{\text {th }}$ percentile drift demand derived from analytical study [Mander et al 2006] are drawn as solid lines in Figure 10. Although these curves may deviate slightly depending on the analytical models used, they essentially serve the same purpose (i.e. communicating seismic risk). For a structure designed for a given drift demand, the probability of failure due to an earthquake can be estimated using these curves. These lines are obtained by conducting nonlinear time-history dynamic analyses using various earthquake records scaled to different intensity and then probabilistically expressing the maximum drift as a function of annual probability of the scaled earthquake records which can be estimated from their intensity using hazard recurrence relationships. The maximum drifts obtained from the analysis using the experimental earthquake records are shown as hollow circles in Figure 10. For the third record, analytical results are not plotted as the analysis predicted collapse before completion of the record. Note that the experimental and analytical drifts are close to each other for the first two records. Following the definition of the three records, EQ1 and EQ3 should correspond to the 90\% non-exceedance probability whereas EQ2 should correspond to the $50 \%$ non-exceedance line. As the $90^{\text {th }}$ percentile drift demand curve passes close to the test data points (dark circles) corresponding to EQ1 and EQ3, and the median drift demand curve passes close to the test data point corresponding to EQ2, the probabilistic drift demand curves are verified.

\section{Conclusions}

Bi-directional PD tests were conducted on three RC piers designed according to the seismic design codes of Caltrans, NZ and Japan. Three earthquake records representing an upper-bound DBE, a median MCE and an upper-bound MCE were sequentially applied to $30 \%$ scaled physical models of these three prototype piers. Based on the experimental investigation reported herein, the following specific conclusions can be drawn.

1. Transportation agencies that own bridges designed to either current United States (Caltrans), New Zealand or Japanese specifications should have a high degree of confidence that their structure should perform well with little residual damage under design basis earthquakes that is the 10 percent probability in 50 year event.

2. Under more severe but rare ground motions that may be characterized as a maximum considered event that has a 2 percent probability in 50 years, owners can be highly confident that their bridges built to Japanese and Caltrans standards should survive without collapse.

3. Under these rare ground motions, owners of bridges designed to New Zealand specifications have less confidence of good performance compared to their US and Japanese counterparts. This is because the New Zealand bridges, although being quite ductile, are somewhat weaker in terms of base shear capacity. They are thus more prone to a toppling failure due to excessive drift of the substructure. Therefore, New Zealand designed piers may not possess 
sufficient strength to survive MCE ground motions with sufficient confidence to ensure the preservation of life-safety. It should thus behove New Zealand transportation agencies to specify a higher level of strength for bridge piers.

\section{References}

Bonelli, A., and Bursi, O. S. (2004). "Generalized- $\alpha$ methods for seismic structural testing." Earthquake Engineering and Structural Dynamics, 33(10), 1067-1102.

Caltrans (1994). Bridge Design Specifications, California Department of Transportation, Sacramento.

Colangelo, F. (2005). "Pseudo-dynamic seismic response of reinforced concrete frames infilled with non-structural brick masonry." Earthquake Engineering and Structural Dynamics, 34(10), 1219-1241.

Darby, A. P., Blakeborough, A., and Williams, M. S. (2001). "Improved control algorithm for real-time substructure testing." Earthquake Engineering and Structural Dynamics, 30(3), 431-448.

Dhakal, R. P., Mander, J. B., and Mashiko, N. (2006). "Identification of critical ground motions for seismic performance assessment of structures." Earthquake Engineering and Structural Dynamics, 35(8), 989-1008.

Dhakal, R. P., and Pan, T. C. (2003). "Characteristics of high-speed cyclic test of beam-column joints.” ACI Structural Journal, 100(2), 188-196.

Hayakawa, R., Kawashima, K., and Watanabe, G. (2003). "Effect of bilateral loadings on the flexural strength and ductility of reinforced concrete bridge piers." JSCE Journal of Earthquake Engineering, 27, 1-4 (in Japanese).

JSCE (1994). Standard Specifications for Concrete Structures, Japan Society of Civil Engineers, Tokyo.

Horiuchi, T., Inoue, M., Konno, T., and Namita, Y. (1999). "Real-time hybrid experiment system with actuator delay compensation and its application to a piping system with energy absorber." Earthquake Engineering and Structural Dynamics, 28(10), 1121-1141.

Mander, J. B., and Basoz, N. (1999). Enhancement of the Highway Transportation Lifeline Module in Hazus, Federal Emergency Management Agency, Washington DC.

Mander, J. B., Dhakal, R. P., and Mashiko, N. (2006). "Incremental dynamic analysis applied to seismic risk assessment of bridges." The Eighth US National Conference in Earthquake Engineering, Paper No 770, CD-ROM, San Francisco, CA.

Molina, F. J., Verzeletti, G., Magonette, G., Buchet, P., and Geradin, M. (1999). "Bi-directional pseudo-dynamic test of a full-size three-storey building." Earthquake Engineering and Structural Dynamics, 28(12), 1541-1566.

Molina, F. J., Sorase, S., Terenzi, G., Magonette, G., and Viaccoz, B. (2004). "Seismic tests on reinforced concrete and steel frames retrofitted with dissipative braces." Earthquake Engineering and Structural Dynamics, 33(15), 1373-1394.

Mosalam, K. M., White, R. N., and Ayala, G. (1998). "Response of infilled frames using pseudodynamic experimentation." Earthquake Engineering and Structural Dynamics, 27(6), 589608.

Mutsuyoshi, H., Machida, A., Tanzo, W., and Mashiko, N. (1994). Inelastic seismic response behaviour of RC bridge pier using pseudo-dynamic test method." Transactions of the Japan Concrete Institute, 16, 265-272.

Nakashima, M., and Masaoka, N. (1999). "Real-time on-line test for MDOF systems." 
Earthquake Engineering and Structural Dynamics, 28(4), 393-420.

Negro, P., and Verzeletti, G. (1996). "Effect of infills on the global behaviour of R/C frames: Energy considerations from pseudo-dynamic tests." Earthquake Engineering and Structural Dynamics, 25(8), 753-773.

NZS3101:95 (1995). Concrete Structures Standard: NZS3101:95, Standards New Zealand, Wellington.

Pan, P., Tada, M., and Nakashima, M. (2005). "Online hybrid test by internet linkage of distributed test-analysis domains." Earthquake Engineering and Structural Dynamics, 34(11), 1407-1425.

Paultre, P., Proulx, J., Mousseau, S., Prevoust, T., and Savard, C. (2003). "Pseudo-dynamic and forced vibration tests of a full-size two-storey reinforced high-performance concrete building." ACI Special Publication SP211-07, 211, 135-160.

Pinto, A. V., Pegon, P., Magonette, G., and Tsionis, G. (2004). Pseudo-dynamic testing of bridges using non-linear substructuring, Earthquake Engineering and Structural Dynamics, 33(11), $1125-1146$.

Takanashi, K., Udagawa, M., Seki, M., Okada, T., and Tanaka, H. (1975). "Nonlinear earthquake response analysis of structures by a computer-actuator on-line system." Bulletin of Earthquake Resistant Structure Research Centre, Institute of Industrial Science, University of Tokyo, Tokyo, Japan.

Tanabe, T. (1999). Comparative Performance of Seismic Design codes for Concrete Structures, Elsevier, New York.

Vamvatsikos, D., and Cornell, C. A. (2004). "Applied incremental dynamic analysis." Earthquake Spectra, 20(2), 523-553.

Zatar, W., and Mutsuyoshi, H. (2002). "Residual displacements of concrete bridge piers subjected to near field earthquakes." ACI Structural Journal, 99(6), 740-749.

Zhang, Y., Sause, R., Ricles, J. M., and Naito, C. J. (2005). "Modified predictor-corrector numerical scheme for real-time pseudo-dynamic tests using state-space formulation." Earthquake Engineering and Structural Dynamics, 34(3), 271-288. 
Table 1 Dimensions of prototypes and test specimens and material properties

\begin{tabular}{|c|c|c|c|c|}
\hline Details of & Parameter & Caltrans & New Zealand & Japan \\
\hline \multirow{7}{*}{ 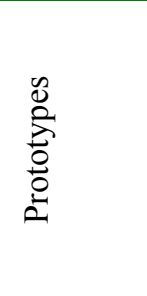 } & Diameter (mm) & 2000 & 1700 & 2000 \\
\hline & Length of plastic hinge zone (mm) & 3000 & 1700 & 4000 \\
\hline & Weight of superstructure (kN) & 7000 & 7000 & 7000 \\
\hline & Longitudinal reinforcing bars & 32-D41 (1.34\%) & 28-D32 (0.99\%) & 28-D51 (1.82\%) \\
\hline & Spiral in plastic hinge & R20@85 (0.78\%) & R20@170 (0.49\%) & R20@115 (0.61\%) \\
\hline & Concrete design strength $(\mathrm{MPa})$ & 25 & 25 & 25 \\
\hline & Bar yield strength (MPa) & 500 & 500 & 500 \\
\hline \multirow{8}{*}{ 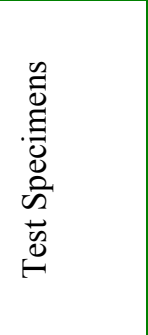 } & Diameter (mm) & 600 & 500 & 600 \\
\hline & Gravity load (kN) & 630 & 630 & 630 \\
\hline & Longitudinal reinforcing bars & 32-D12 (1.28\%) & $24-\mathrm{D} 10(0.96 \%)$ & 24-D16 (1.71\%) \\
\hline & Length of plastic hinge zone (mm) & 900 & 500 & 1200 \\
\hline & Spirals in plastic hinge & R6@25 (0.83\%) & R6@50 (0.51\%) & R6@35 (0.60\%) \\
\hline & Concrete measured strength (MPa) & 40.7 & 41.2 & 38.5 \\
\hline & Main bar yield strength $(\mathrm{MPa})$ & 528 & 539 & 517 \\
\hline & Spiral yield strength (MPa) & 461 & 461 & 461 \\
\hline
\end{tabular}


Figure 1 Typical prototype bridge pier and pushover curves of the three prototypes

Figure 2 Pseudo-dynamic (PD) test setup

Figure 3 Instrumentation and data acquisition system

Figure 4 Bi-directional pseudodynamic test concept

Figure 5 Earthquake records used in the PD tests

Figure 6 Experimental results of the Caltrans pier showing: (a) Bi-directional drift orbit; (b)

Load-displacement curve; (c) Time-history of the drift; (d) Photograph showing cover spalling at drift of 3.7\%; and (e) Photograph at the end of the test

Figure 7 Experimental results of the New Zealand pier showing: (a) Bi-directional drift orbit; (b)

Load-displacement curve; (c) Time-history of the drift; (d) Photograph showing bar

buckling at a drift of $3.6 \%$; and (e) Photograph at the end of the test

Figure 8 Experimental results of the Japanese pier showing: (a) Bi-directional drift orbit; (b)

Load-displacement curve; (c) Time-history of the drift; (d) Photograph showing cover spalling at a drift of 2.7\%; and (e) Photograph at the end of the test

Figure 9 Comparison of the seismic performance of the three specimens

Figure 10 Assessment of seismic risk using the probabilistic drift demand curves 

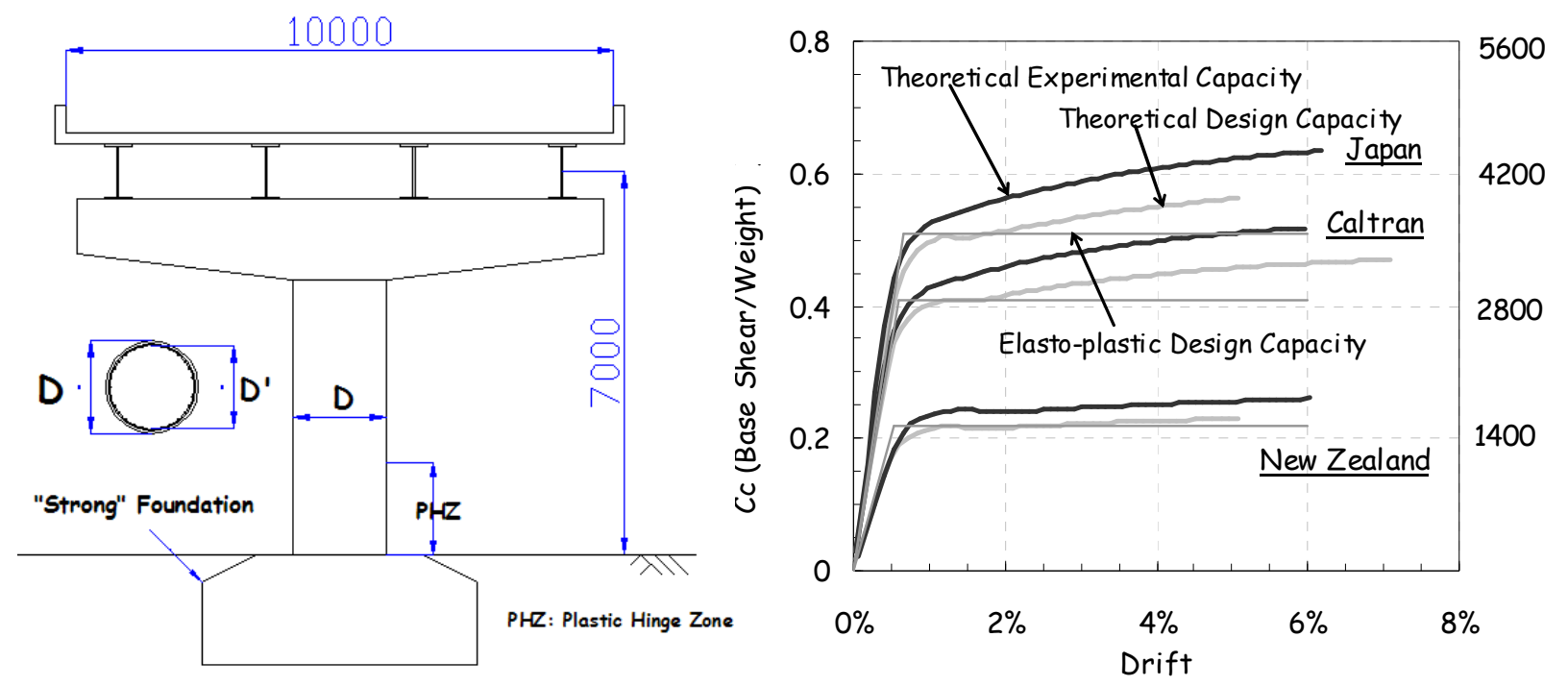

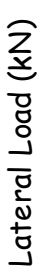

Figure 1 Typical prototype bridge pier and pushover curves of the three prototypes 


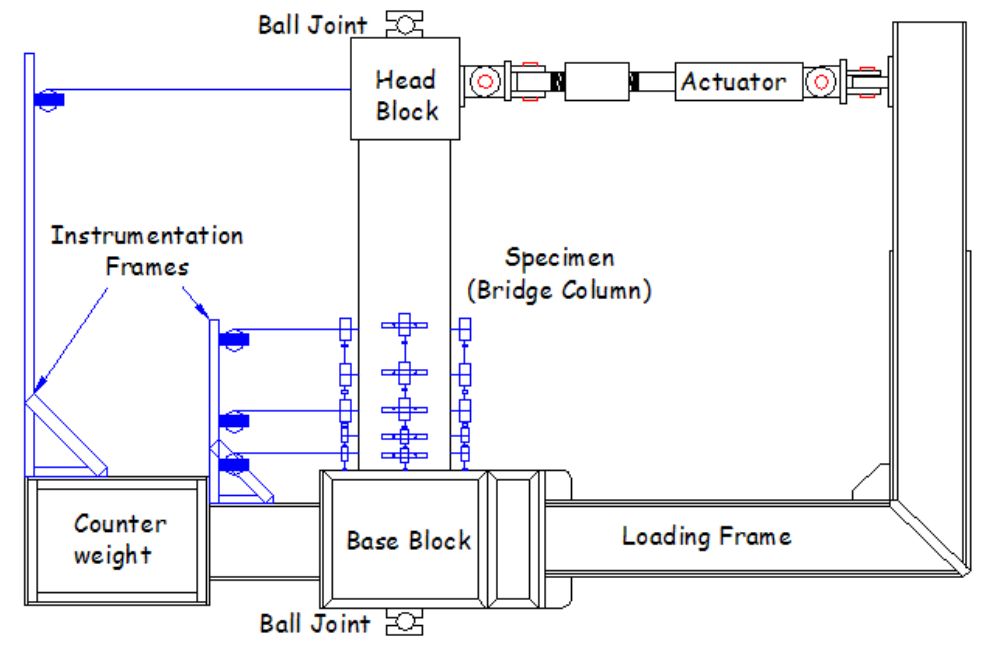

a. Elevation view

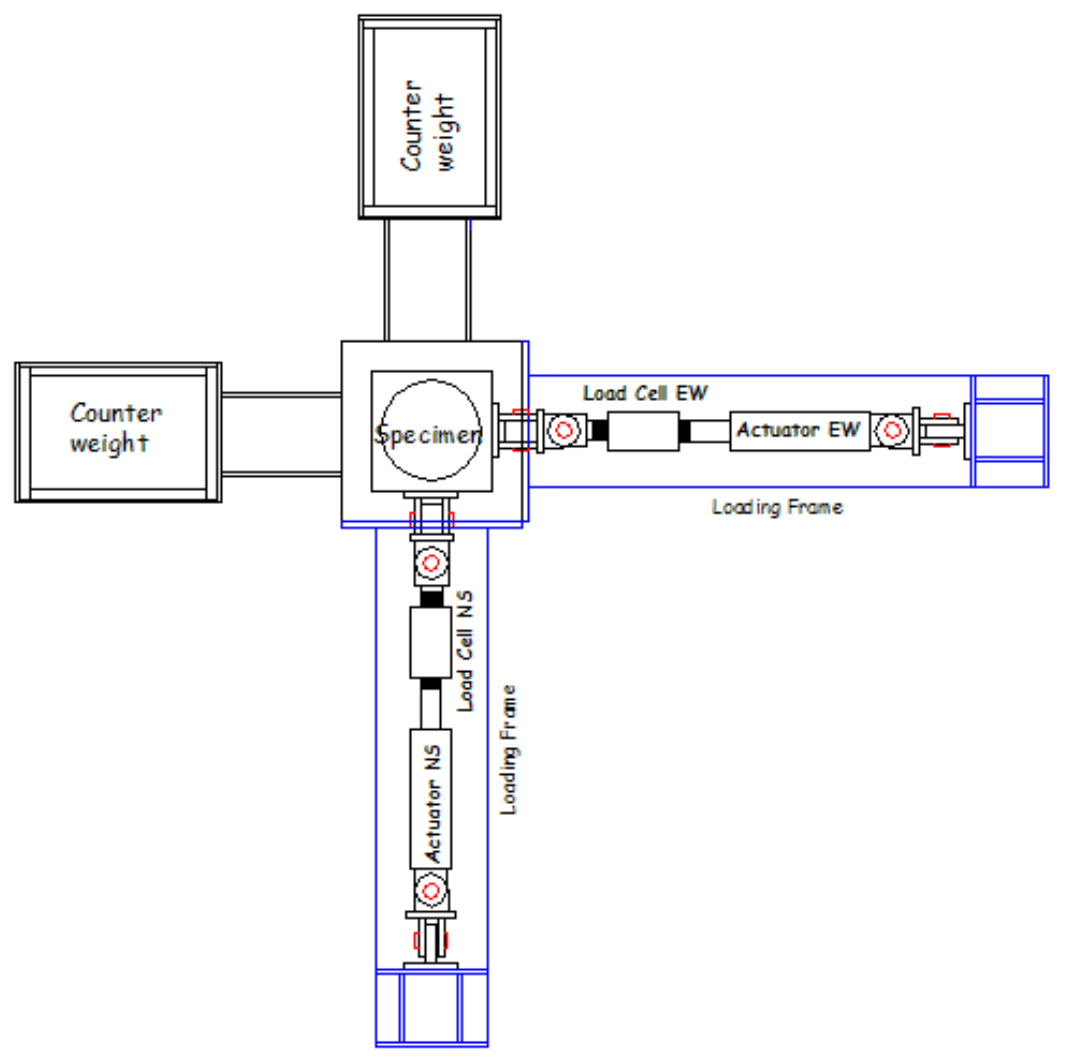

b. Plan view

Figure 2 Pseudo-dynamic (PD) test setup 


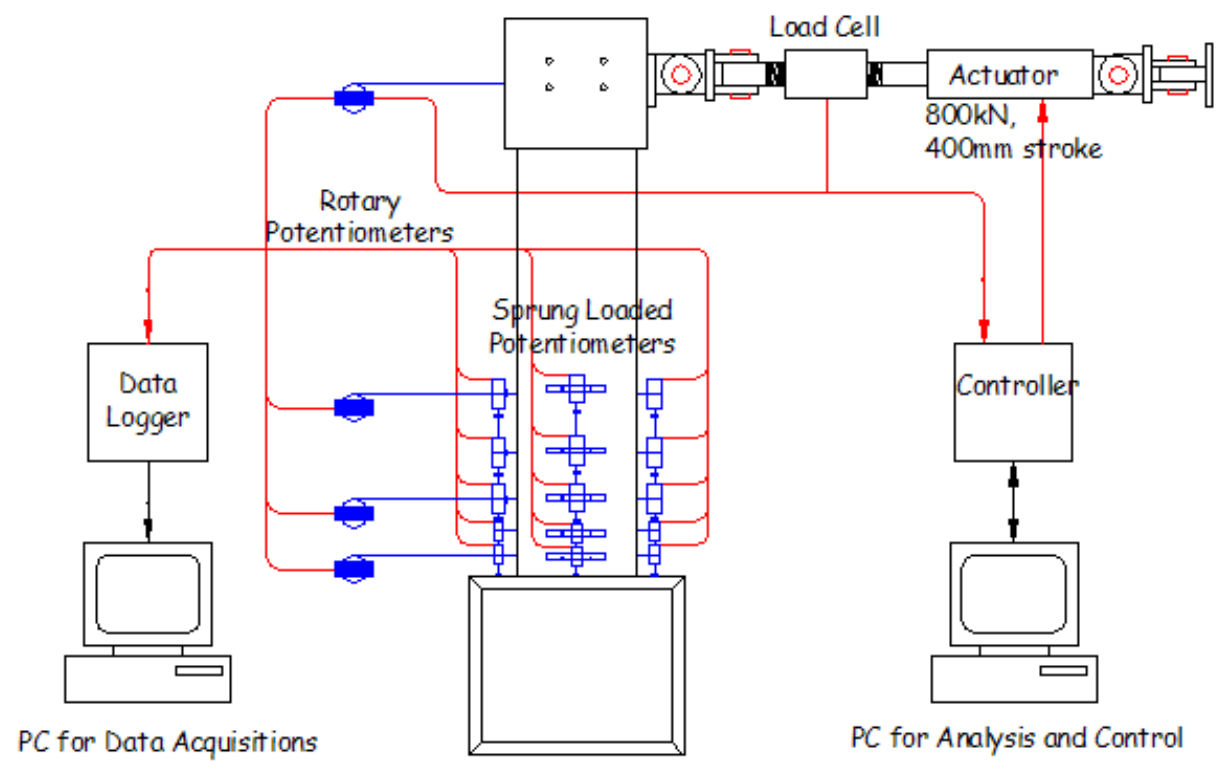

Figure 3 Instrumentation and data acquisition system 




Figure 4 Bi-directional pseudodynamic test concept 

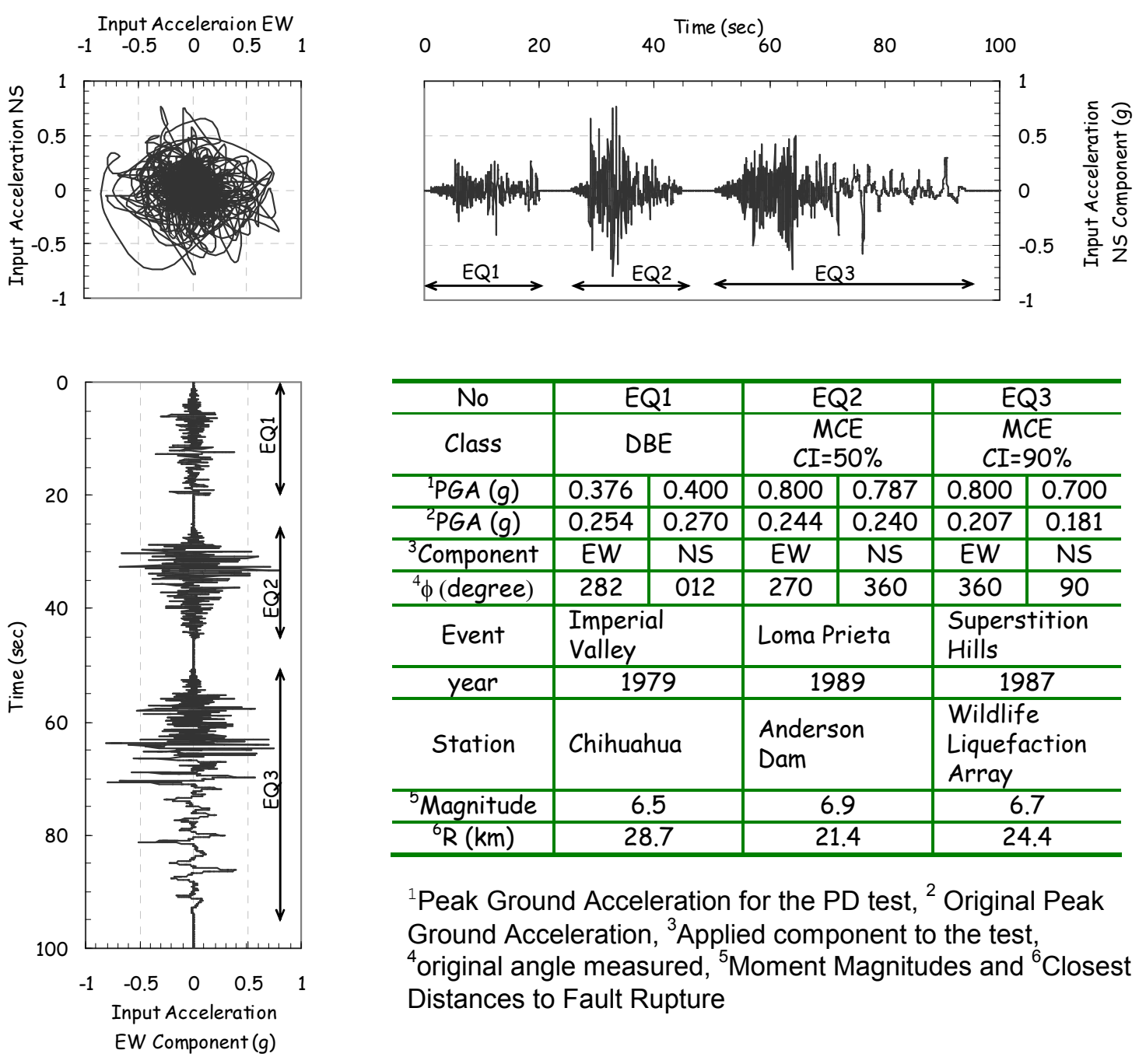

\begin{tabular}{|c|c|c|c|c|c|c|}
\hline No & \multicolumn{2}{|c|}{ EQ1 } & \multicolumn{2}{|c|}{ EQ2 } & \multicolumn{2}{|c|}{ EQ3 } \\
\hline Class & \multicolumn{2}{|c|}{ DBE } & \multicolumn{2}{|c|}{$\begin{array}{c}M C E \\
C I=50 \%\end{array}$} & \multicolumn{2}{|c|}{$\begin{array}{c}M C E \\
C I=90 \%\end{array}$} \\
\hline${ }^{1} P G A(g)$ & 0.376 & 0.400 & 0.800 & 0.787 & 0.800 & 0.700 \\
\hline${ }^{2} P G A(g)$ & 0.254 & 0.270 & 0.244 & 0.240 & 0.207 & 0.181 \\
\hline${ }^{3}$ Component & EW & NS & EW & NS & EW & NS \\
\hline${ }^{4} \phi($ degree $)$ & 282 & 012 & 270 & 360 & 360 & 90 \\
\hline Event & \multicolumn{2}{|c|}{$\begin{array}{l}\text { Imperial } \\
\text { Valley }\end{array}$} & \multicolumn{2}{|c|}{ Loma Prieta } & \multicolumn{2}{|c|}{$\begin{array}{l}\text { Superstition } \\
\text { Hills }\end{array}$} \\
\hline year & \multicolumn{2}{|c|}{1979} & \multicolumn{2}{|c|}{1989} & \multicolumn{2}{|c|}{1987} \\
\hline Station & \multicolumn{2}{|c|}{ Chihuahua } & \multicolumn{2}{|c|}{$\begin{array}{l}\text { Anderson } \\
\text { Dam }\end{array}$} & \multicolumn{2}{|c|}{$\begin{array}{l}\text { Wildlife } \\
\text { Liquefaction } \\
\text { Array }\end{array}$} \\
\hline${ }^{5}$ Magnitude & \multicolumn{2}{|c|}{6.5} & \multicolumn{2}{|c|}{6.9} & \multicolumn{2}{|c|}{6.7} \\
\hline${ }^{6} \mathrm{R}(\mathrm{km})$ & \multicolumn{2}{|c|}{28.7} & \multicolumn{2}{|c|}{21.4} & \multicolumn{2}{|c|}{24.4} \\
\hline
\end{tabular}

${ }^{1}$ Peak Ground Acceleration for the PD test, ${ }^{2}$ Original Peak Ground Acceleration, ${ }^{3}$ Applied component to the test, ${ }^{4}$ original angle measured, ${ }^{5}$ Moment Magnitudes and ${ }^{6}$ Closest Distances to Fault Rupture

Figure 5 Earthquake records used in the PD tests. 

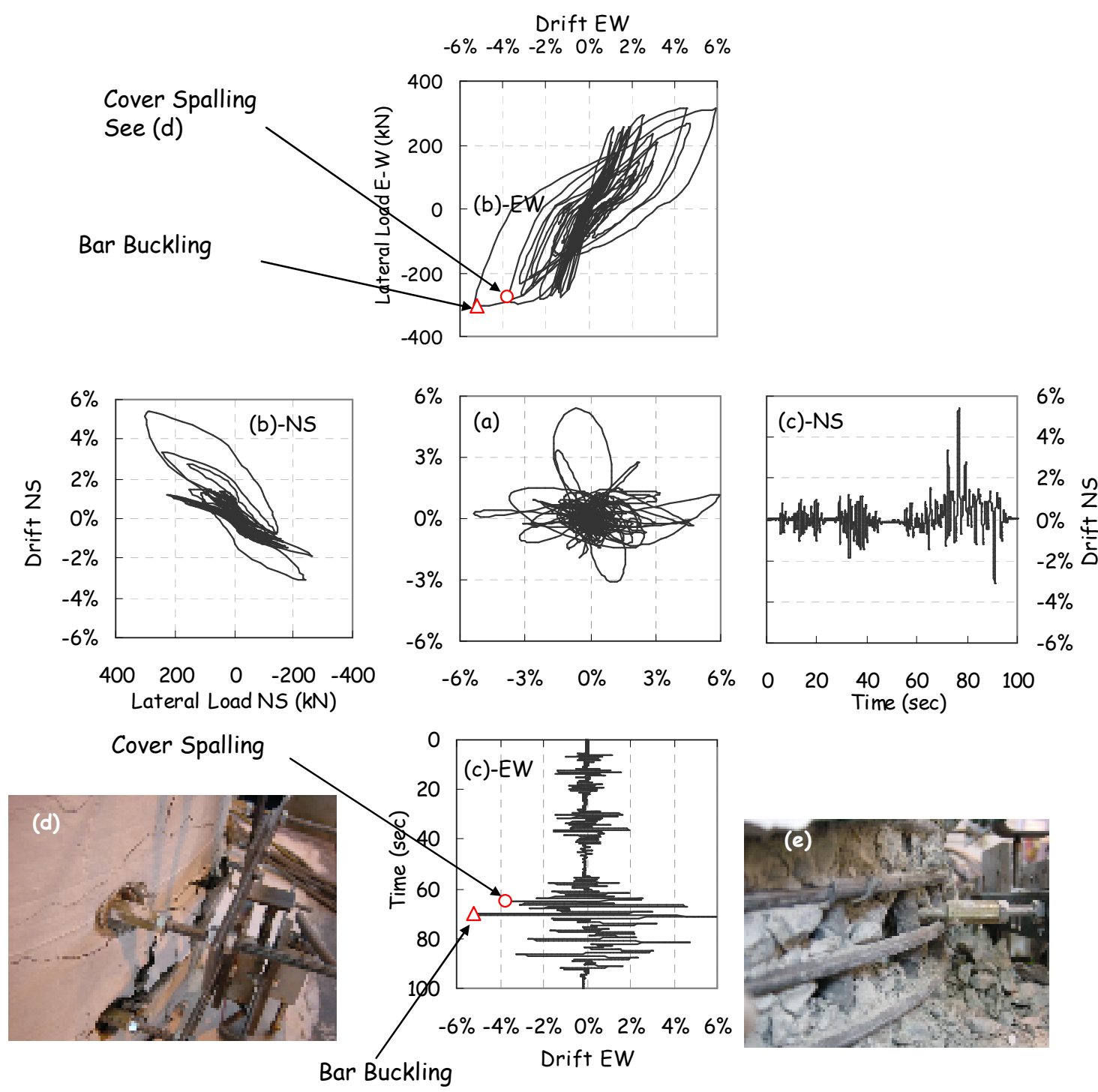

Figure 6 Experimental results of the Caltrans pier showing (a) Bi-directional drift orbit; (b) Load-displacement curve; (c) Time-history of the drift; (d) Photograph showing cover spalling at drift of 3.7\%; and (e) Photograph at the end of the test. 

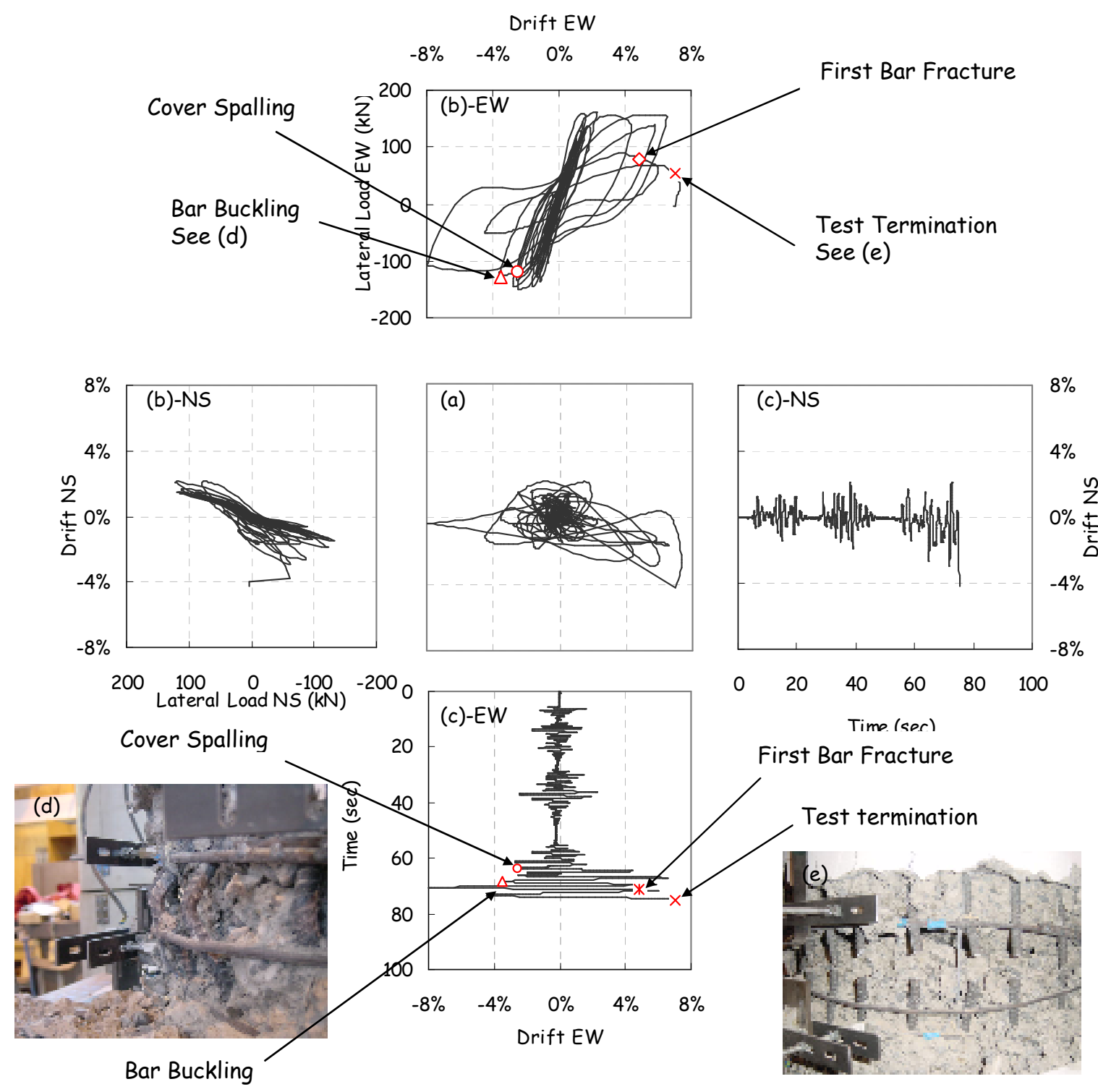

Figure 7 Experimental results of the New Zealand pier showing (a) Bi-directional drift orbit; (b) Load-displacement curve; (c) Time-history of the drift; (d) Photograph showing bar buckling at a drift of 3.6\%; and (e) Photograph at the end of the test. 

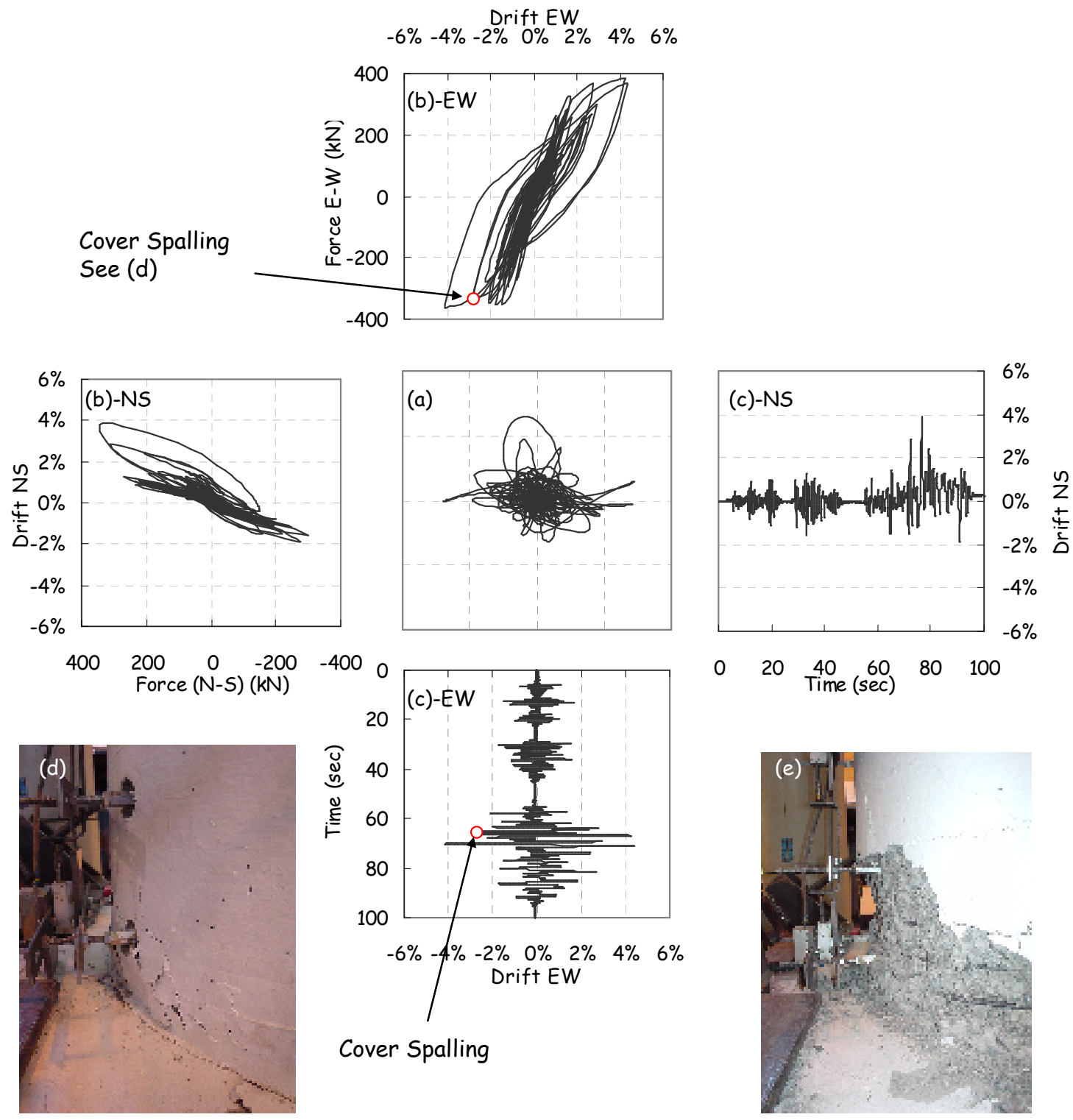

Cover Spalling

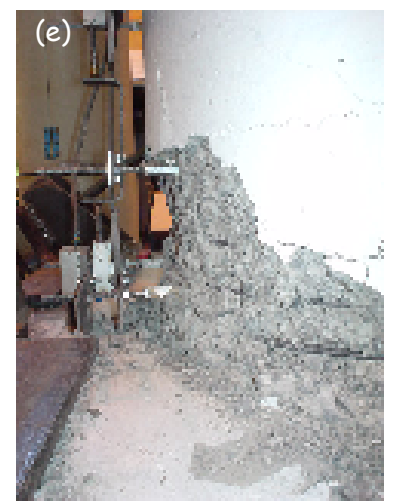

Figure 8 Experimental results of the Japanese pier showing (a) Bi-directional drift orbit; (b) Load-displacement curve; (c) Time-history of the drift; (d) Photograph showing cover spalling at a drift of 2.7\%; and (e) Photograph at the end of the test. 


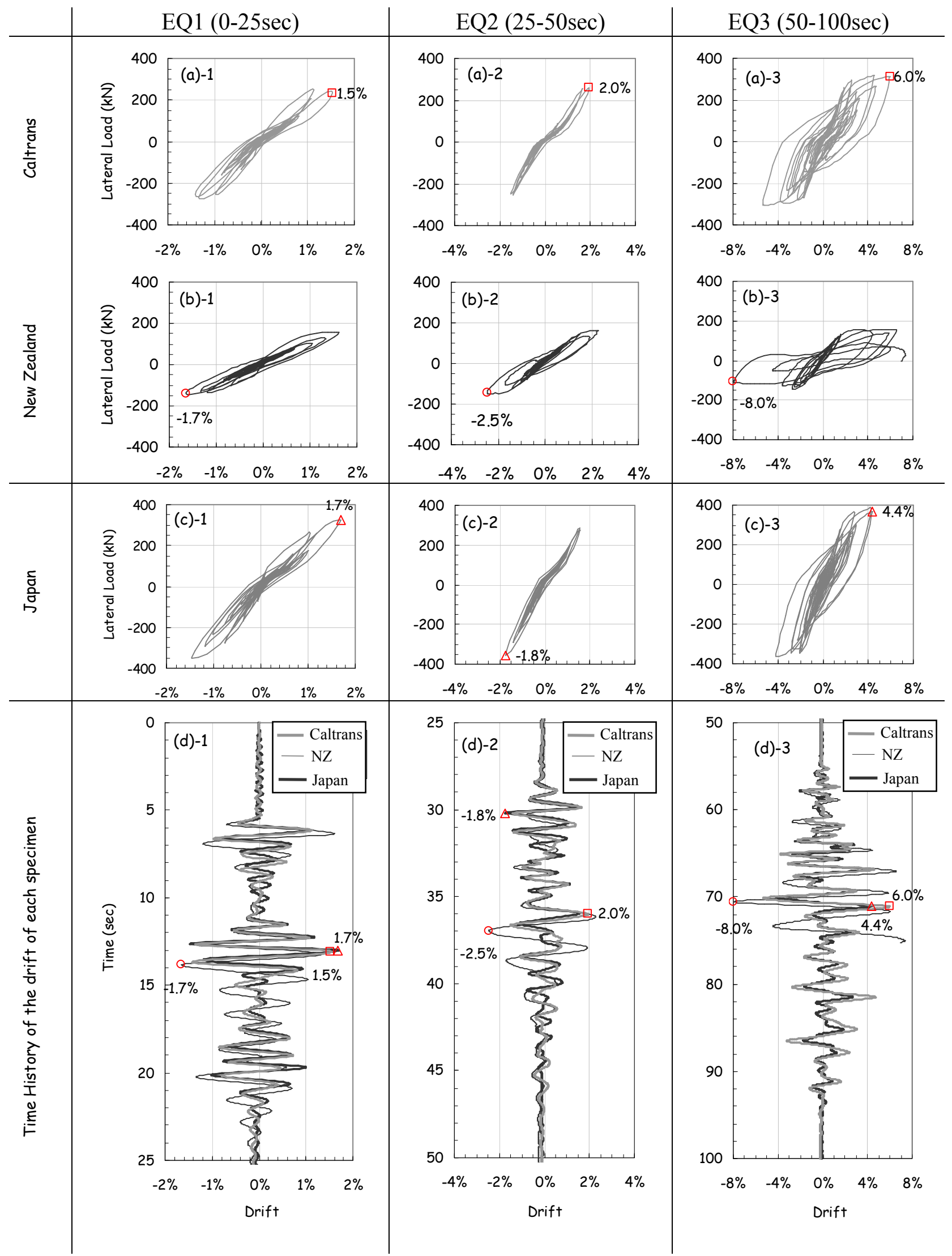

Figure 9 Comparison of the seismic performance of the three specimens. 


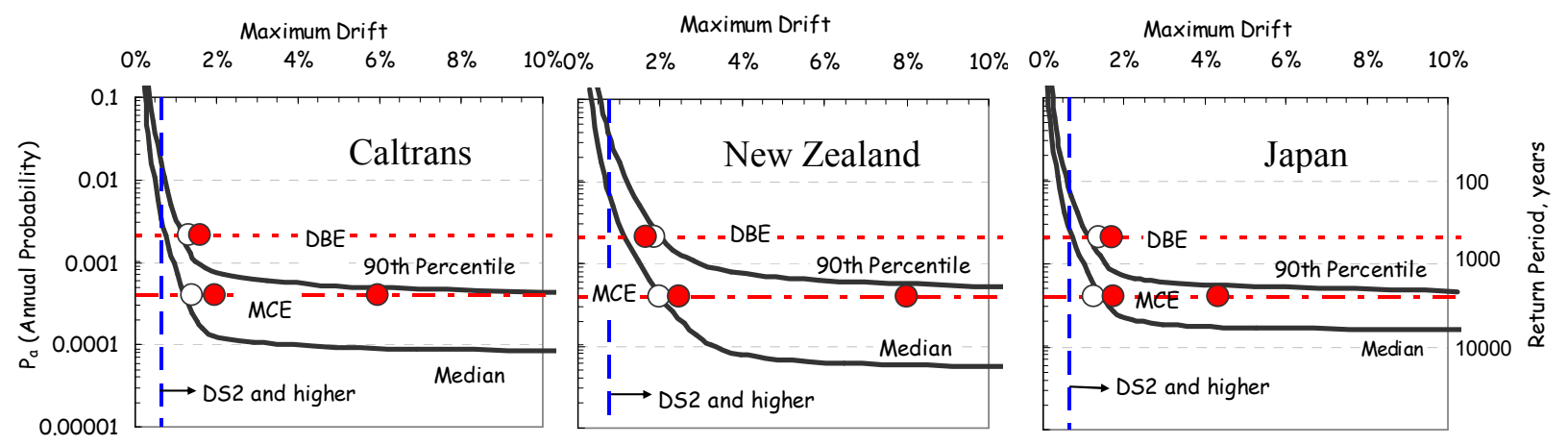

Figure 10 Assessment of seismic risk using the probabilistic drift demand curves 